\title{
New reliable scoring system, Toyama mouse score, to evaluate locomotor function following spinal cord injury in mice
}

\author{
Michiko Shigyo ${ }^{1}$, Norio Tanabe ${ }^{1}$, Tomoharu Kuboyama ${ }^{1}$, Song-Hyen Choi $^{2}$ and Chihiro Tohda ${ }^{1 *}$
}

\begin{abstract}
Background: Among the variety of methods used to evaluate locomotor function following a spinal cord injury (SCI), the Basso Mouse Scale score (BMS) has been widely used for mice. However, the BMS mainly focuses on hindlimb movement rather than on graded changes in body support ability. In addition, some of the scoring methods include double or triple criteria within a single score, which likely leads to an increase in the deviation within the data.

Therefore we aimed to establish a new scoring method reliable and easy to perform in mice with SCI.

Findings: Our Toyama Mouse Score (TMS) was established by rearranging and simplifying the BMS score and combining it with the Body Support Scale score (BSS). The TMS reflects changes in both body support ability and hindlimb movement. The definition of single score is made by combing multiple criteria in the BMS. The ambiguity was improved in the TMS. Using contusive SCI mice, hindlimb function was measured using the TMS, BMS and BSS systems. The TMS could distinguish changes in hindlimb movements that were evaluated as the same score by the BMS. An analysis of the coefficient of variation (CV) of score points recorded for 11 days revealed that the CV for the TMS was significantly lower than the CV obtained using the BMS. A variation in intra evaluators was lower in the TMS than in the BMS.
\end{abstract}

Conclusion: These results suggest that the TMS may be useful as a new reliable method for scoring locomotor function for $\mathrm{SCl}$ models.

Keywords: Spinal cord injury, Hindlimb movement, Mouse, New scoring, TMS

\section{Findings \\ Background}

A variety of methods to evaluate locomotor function following SCI have been proposed and modified over time. Especially, open field locomotion has become a widely used and important means of evaluation for SCI models because it is easily accessible (no required instruments). Among these methods, the Basso-Beattie-Bresnahan scoring (BBB) system [1] has been widely used in the rat model. However, BBB is not as suitable for evaluation in a mouse model. Therefore, Basso et al. developed a new scoring method for mice, the Basso Mouse Scale score (BMS) [2].

In the BMS, score 3 reflects the threshold at which the animal can support its own body weight. The

\footnotetext{
* Correspondence: chihiro@inm.u-toyama.ac.jp

${ }^{1}$ Division of Neuromedical Science, Institute of Natural Medicine, University of Toyama, 2630 Sugitani, Toyama 930-0194, Japan

Full list of author information is available at the end of the article
}

potency of supporting the body trunk is graded according to the functional improvement. However, beyond score 3 , stepping frequency and consistency are the primary factors evaluated, suggesting that the BMS fails to detect differences in ability of body support. Therefore, we proposed the Body Support Scale score (BSS) an additional criterion for functional evaluation [3].

Some points of the BMS still should be improved. Double or triple criteria are considered to determine for scores 3, 5, 6, 7 and 8, so that a broad range of functional states may be classified in a single score in BMS. In this study, we propose a new scoring system named the Toyama Mouse Score (TMS) that is based on a combination of the BMS and BSS with modifications. The TMS is easy to access, and offers a clear-cut summative pointing system, resulting in better evaluation with high sensitivity and low variation.

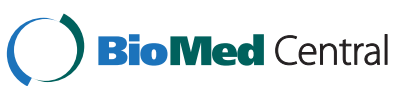

(c) 2014 Shigyo et al.; licensee BioMed Central Ltd. This is an Open Access article distributed under the terms of the Creative Commons Attribution License (http://creativecommons.org/licenses/by/2.0), which permits unrestricted use, distribution, and reproduction in any medium, provided the original work is properly credited. The Creative Commons Public Domain Dedication waiver (http://creativecommons.org/publicdomain/zero/1.0/) applies to the data made available in this article, unless otherwise stated. 


\section{Methods}

\section{Spinal cord injury}

The committee for Animal Care and use at the University of Toyama approved each of the study protocols. Six-week-old male (Figure 1, Table 1) and 8-week-old female (Table 2) ddY mice (SLC, Shizuoka, Japan) were used in the SCI experiments. The mice were anesthetized by the administration of trichloroacetaldehyde monohydrate $\left(500 \mathrm{mg} \mathrm{kg}^{-1}\right.$, i.p.). After confirming the mice were completely under anesthesia by pinching the hindpaw, the surgical operation to induce SCI was performed, as previously described [4] with slight modifications. After laminectomy at the T11 vertebrae level, contusion injuries were given by dropping a 6.5 -g weight (the tip diameter : $1 \mathrm{~mm}$ ) from a height of $30 \mathrm{~mm}$ onto the exposed dura mater of the lumbar spinal cord at the L1 level using stereotaxic instrument (Narishige, Tokyo, Japan). The injured mice hardly move their hindlimbs at 1 day post injury (dpi) and come to recover gradually as time goes by, and we have gotten reproducible data about it [3].

\section{Locomotor evaluation}

For behavioral scoring, the mice were individually placed in an open-field $(42 \mathrm{~cm} \times 48 \mathrm{~cm} \times 15 \mathrm{~cm})$ and observed for 5 min once a day until 11 days post injury. In the
Table 1 TMS, BMS and CV values for 6 hindlimbs at 4 days post injury evaluated by single observer

\begin{tabular}{lll}
\hline & TMS & BMS \\
\hline Hindlimb 1 & 1 & 0 \\
Hindlimb 2 & 1 & 0 \\
Hindlimb 3 & 0 & 0 \\
Hindlimb 4 & 3 & 2 \\
Hindlimb 5 & 4 & 2 \\
Hindlimb 6 & 4 & 2 \\
CV & 0.795 & 1.095 \\
\hline
\end{tabular}

control group, naive ddY mice were observed for 5 days. Open field locomotion was evaluated using the $0-8$ point BMS score (without tail score), the 0-4 point BSS score and the $0-30$ point TMS. Animals were allowed to move freely in the plastic box. The movement of the left and right hindlimbs was evaluated independently.

\section{Statistical analysis}

Statistical tests were performed using GraphPad Prism software (version 5; GraphPad Software, Inc., San Diego, CA). Differences in the scores were analyzed using unpaired $t$-tests. The coefficient of variation $(\mathrm{CV})$ was

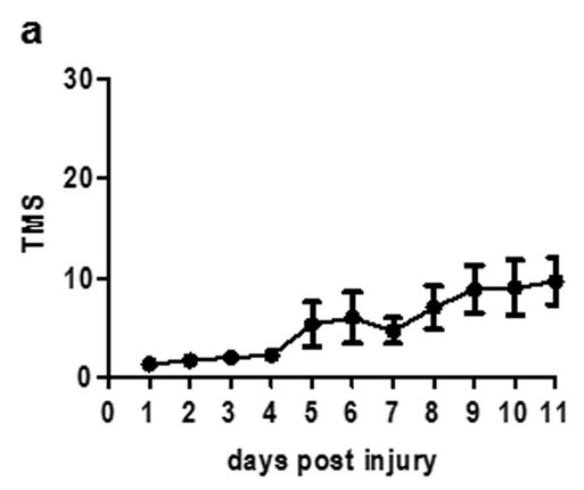

\section{b}
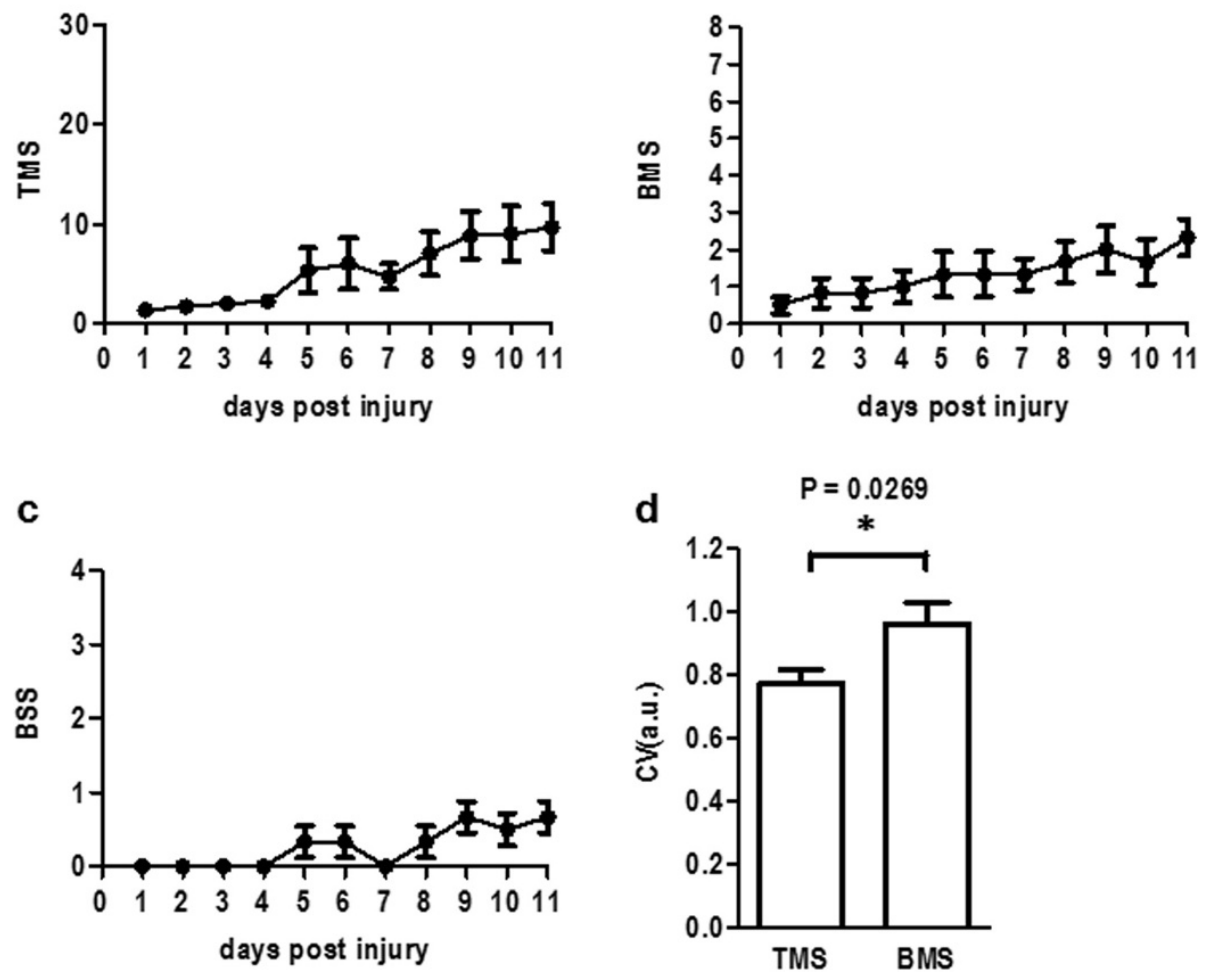

Figure 1 Hindlimb function in SCI mice evaluated by TMS, BMS and BSS. The locomotor function of SCl mice was evaluated by using the TMS (a), BMS (b) and BSS (c) for 11 days post injury (a total of 3 mice per group, $n=6$ hindlimbs). Coefficients of variation (CV) for the TMS and BMS were calculated for each of the 11 days (d). The TMS yielded a significantly lower CV than did the BMS ( $p=0.0269,{ }^{*} p<0.05$, unpaired $t$-test). 
Table 2 TMS, BMS and CV values for one hindlimb at 3 days post injury evaluated by 8 observers

\begin{tabular}{lll}
\hline & TMS & BMS \\
\hline Observer 1 & 3 & 1 \\
Observer 2 & 0 & 0 \\
Observer 3 & 1 & 0 \\
Observer 4 & 3 & 1 \\
Observer 5 & 0 & 0 \\
Observer 6 & 1 & 0 \\
Observer 7 & 1 & 0 \\
Observer 8 & 2 & 0 \\
CV & 0.864 & 1.852 \\
\hline
\end{tabular}

calculated as follows; $\mathrm{CV}=$ standard deviation/mean value. $P$ values $<0.05$ were considered significant.

\section{Results}

SCI mice were observed in an open field and scored using the TMS (Figure 1a), BMS (Figure 1b) and BSS (Figure 1c) for 11 days after SCI. A TMS point table is shown in Table 3. Categories of criteria for the TMS were determined by according to the BMS subscore [2] with modification. We think that body support ability is very important functional outcome and should be weighted equally to other issues. Therefore, in the TMS, the maximum score for body support was 15 points, and the maximum summed score of other issues was also 15 points. Observations were performed for 9 items, and the points were simply summed. Table 4 shows focused points for observation in the TMS, BMS and BSS. The TMS observes a frequency of ankle movement,
Table 4 Focused points in TMS, BMS and BSS

\begin{tabular}{|c|c|c|c|c|}
\hline \multicolumn{2}{|l|}{ Criteria } & \multirow{2}{*}{$\frac{\text { TMS }}{G}$} & \multirow{2}{*}{ BMS } & \multirow{2}{*}{$\begin{array}{c}\text { BSS } \\
-\end{array}$} \\
\hline Ankle movement & Frequency & & & \\
\hline & Mobile extent & G & G & - \\
\hline Movement in other joints & & $Y / N$ & - & - \\
\hline Toe movement & & $Y / N$ & - & - \\
\hline \multirow[t]{2}{*}{ Touchable area of the sole } & at Resting & G & $\mathrm{Y} / \mathrm{N}$ & $Y / N$ \\
\hline & at Stepping & G & G & - \\
\hline \multicolumn{2}{|l|}{ Coordination } & $Y / N$ & G & - \\
\hline \multicolumn{2}{|c|}{ Hindlimb movement at stepping } & G & G & - \\
\hline \multicolumn{2}{|l|}{ Body supporting } & G & $\mathrm{Y} / \mathrm{N}$ & G \\
\hline
\end{tabular}

movement of knees, thighs and toes, which are not checked in the BMS measurement. To compare the precision of the TMS and BMS, we calculated the coefficients of variations $(\mathrm{CV})$ of the data in the 11-day observation periods. $\mathrm{CV}$ values are used to evaluate relative variations of data obtained in different criteria. The averaged $\mathrm{CV}$ of the TMS data was significantly lower than that of the BMS scores $(p=0.0269)$ (Figure $1 \mathrm{~d})$. We additionally performed two independent series of these experiments. The results consistently indicated that CV of the TMS data was significantly smaller than the CV of the BMS data (experiment 1 ; CV in TMS $=1.1274, \mathrm{CV}$ in $\mathrm{BMS}=$ 1.4269, $p=0.0286$ ) (experiment 2 ; CV in TMS $=0.7627$, $\mathrm{CV}$ in $\mathrm{BMS}=1.3560, p=0.0399)$. To compare the sensitivity between the TMS and BMS, data of 6 hindlimbs at 4 days post injury were picked up from Figure 1

Table 3 TMS point table for the open field locomotor performance of SCI mice

\begin{tabular}{|c|c|c|c|c|c|c|c|c|c|c|c|c|c|c|c|c|c|}
\hline \multicolumn{4}{|c|}{ Ankle movement } & \multirow{2}{*}{\multicolumn{2}{|c|}{$\begin{array}{l}\text { Movement } \\
\text { in other } \\
\text { joints }\end{array}$}} & \multirow{2}{*}{\multicolumn{2}{|c|}{$\begin{array}{c}\text { Toe } \\
\text { movement }^{4)}\end{array}$}} & \multicolumn{4}{|c|}{ Touchable area of the sole } & \multirow{2}{*}{\multicolumn{2}{|c|}{ Coordination $^{5)}$}} & \multirow{2}{*}{\multicolumn{2}{|c|}{$\begin{array}{l}\text { Hindlimb } \\
\text { movement } \\
\text { at stepping }\end{array}$}} & \multirow{2}{*}{\multicolumn{2}{|c|}{$\begin{array}{c}\text { Body } \\
\text { supporting }\end{array}$}} \\
\hline Frequen & $\mathrm{cy}^{1)}$ & $\begin{array}{l}\text { Mobil } \\
\text { extent }\end{array}$ & & & & & & \multicolumn{2}{|c|}{ At resting } & \multicolumn{2}{|l|}{ At stepping } & & & & & & \\
\hline No $(0)$ & 0 & No $(0)$ & 0 & No & 0 & No & 0 & No & 0 & No & 0 & No & 0 & No & 0 & No & 0 \\
\hline$<50 \%$ & 1 & $<50 \%$ & 1 & Yes & 1 & Yes & 1 & $\begin{array}{c}\text { Partial } \\
\text { sole touch }\end{array}$ & 1 & $\begin{array}{l}\text { Partial sole } \\
\text { touch }\end{array}$ & 1 & Yes & 1 & Rotative & 1 & $\begin{array}{l}\text { Sometimes support } \\
\text { of hind body trunk }\end{array}$ & 5 \\
\hline \multirow[t]{3}{*}{$\geq 50 \%$} & 2 & $\geq 50 \%$ & 2 & & & & & $\begin{array}{l}\text { Full sole } \\
\text { touch }\end{array}$ & 2 & $\begin{array}{l}\text { Full sole touch, } \\
\text { frequency }<50 \%\end{array}$ & 2 & & & Parallel & 2 & $\begin{array}{l}\text { Always support of the } \\
\text { body trunk, but } \\
\text { unstable weight support }\end{array}$ & 10 \\
\hline & & & & & & & & & & $\begin{array}{l}\text { Full sole touch, } \\
\text { frequency } \geq 50 \%\end{array}$ & 3 & & & & & $\begin{array}{l}\text { Always support of the } \\
\text { body trunk, and stable } \\
\text { weight support }\end{array}$ & 15 \\
\hline & & & & & & & & & & $\begin{array}{l}\text { Full sole tohch } \\
\text { in every steps }\end{array}$ & 4 & & & & & & \\
\hline
\end{tabular}

\footnotetext{
Definitions

${ }^{1)}$ Frequency: a ratio of the number of stepping forward with the ankle movement in all steppings.

${ }^{2)}$ Mobile extent: Mobile extent observed in a normal mouse is defined as $100 \%$.

${ }^{3)}$ Movement of the knee joint or hip joint.

${ }^{4)}$ Toe movement: Toes movement, but not spasm.

${ }^{5)}$ Coordination: Correspondence between the forelimbs and hindlimbs in steppings.
} 
(Table 1). As a result by single observer, three hindlimbs evaluated similarly as score 0 by the BMS were distinguish as point 0 or 1 in the TMS. Also, three hindlimbs evaluated as score 2 by the BMS were judged as points 3 or 4 in the TMS. The CV value of the TMS was also lower than that of the BMS at the point. These results suggest the fine sensitivity of the TMS. In an independent experiment, score points observed by different observers for one hindlimb at 3 days post injury were picked up to compare variations in intra evaluators between the TMS and BMS (Table 2). The results showed low CV value of the TMS compared with CV of the BMS, suggesting that TMS provides lower variation in intra observers than BMS. A similar tendency was observed also in other mice. Naive mice without injury were observed for 5 days by 6 observers. The TMS, BMS and BSS were shown in full scores by all observers. These results suggest that the TMS provides reliable data with little deviation.

\section{Discussion}

We established a new method to evaluate SCI mice, the TMS by rearranging and simplifying the BMS and combining it with the BSS. The TMS provided a low coefficient of variation relative to the BMS in SCI mice. The decision for each factor on the TMS is easy because the criteria are clear. In contrast, the BMS yielded larger deviations than the TMS did in intra samples (Figure $1 \mathrm{~d}$ and Table 1) and in intra observers (Table 2). This larger deviation denotes that scores both higher and lower than the actual value are liable to arise when using the BMS. The TMS reflects changes in both hindlimb movement and body support ability. Since the ambiguous combination of double or triple criteria within a single score is used to judge in the BMS, the ambiguity was improved in the TMS. The TMS also could distinguish slight differences in hindlimb function, which are not detected in the BMS, especially when the score is low (Table 1 and Table 2). The summation system of the TMS does not miss the movement of multiple joints in hindlimbs and toes, and the paw position at resting as well as at walking, resulting in detection of slight changes.

Other groups have also reported improved scoring methods for evaluating SCI mice. The mBBB is an optimized version of the $\mathrm{BBB}$ that has been adapted to mice by combining BBB with a walking test on the bar [5], but its use has not spread. The probable drawback to this method is that it is time consuming to perform a walking test. The BLG score [6] was developed by combining the BMS-, with the ladder and grip tests. Here, several instruments are needed to evaluate each criterion. In contrast, the TMS requires only an open box to evaluate SCI mice, making the present system very simple to perform. Our findings suggest that the TMS should be useful as a new reliable scoring system for evaluating SCI mice.

\section{Competing interests}

The authors declare that they have no competing interest related to this study.

\section{Author's contributions}

MS, NT and TK decided the criteria of TMS. NT and SC performed SCI surgery and observation. MS and NT analyzed the data. TK and CT conducted the experiment. MS and CT wrote the manuscript. All authors approved the final manuscript.

\section{Acknowledgments}

We express our gratitude to Mr. Yoshitaka Tanie, Mr. Zhi-you Yang, Miss Ximeng Yang and Miss Nagisa Kudo for their assistance. This work was partially supported by Grants-in-Aid for Scientific Research (C) (23500439, C.T.), and Grants-in-Aid for Scientific Research for Young Scientists (B) (23700376, T.K.) from the Ministry of Education, Culture, Sports, Science and Technology of Japan-, and Natural Medicine and Biotechnology Research, Toyama Prefecture, Japan (C.T., and T.K.).

\section{Author details}

'Division of Neuromedical Science, Institute of Natural Medicine, University of Toyama, 2630 Sugitani, Toyama 930-0194, Japan. ²Dong-A ST Pharm. Research Center, 47-5 Sanggal-dong, Giheung-gu, Yongin-si, Gyeonggi-do 446-905, Republic of Korea.

Received: 31 October 2013 Accepted: 26 May 2014

Published: 3 June 2014

\section{References}

1. Basso DM, Beattie MS, Bresnahan JC: A sensitive and reliable locomotor rating scale for open field testing in rats. J Neurotrauma 1995, 12:1-21.

2. Basso DM, Fisher LC, Anderson AJ, Jakeman LB, McTigue DM, Popovich PG: Basso mouse scale for locomotion detects differences in recovery after spinal cord injury in five common mouse strains. J Neurotrauma 2006, 23:635-659.

3. Teshigawara K, Kuboyama T, Shigyo M, Nagata A, Sugimoto K, Matsuya Y, Tohda C: A novel compound, denosomin, ameliorates spinal cord injury via axonal growth associated with astrocyte-secreted vimentin. $\mathrm{Br} J$ Pharmacol 2013, 168:903-919.

4. Krenz NR, Weaver LC: Nerve growth factor in glia and inflammatory cells of the injured rat spinal cord. J Neurochem 2000, 74:730-739.

5. Li Y, Oskouian RJ, Day YJ, Kern JA, Linden J: Optimization of a mouse locomotor rating system to evaluate compression-induced spinal cord injury: correlation of locomotor and morphological injury indices. J Neurosurg Spine 2006, 4:165-173.

6. Pajoohesh-Ganji A, Byrnes KR, Fatemi G, Faden Al: A combined scoring method to assess behavioral recovery after mouse spinal cord injury. Neurosci Res 2010, 67:117-125.

doi:10.1186/1756-0500-7-332

Cite this article as: Shigyo et al:: New reliable scoring system, Toyama mouse score, to evaluate locomotor function following spinal cord injury in mice. BMC Research Notes 2014 7:332.

\section{Submit your next manuscript to BioMed Central and take full advantage of:}

- Convenient online submission

- Thorough peer review

- No space constraints or color figure charges

- Immediate publication on acceptance

- Inclusion in PubMed, CAS, Scopus and Google Scholar

- Research which is freely available for redistribution 